\title{
An efficient synthesis of quinolines under solvent-free conditions
}

\author{
MIHIR K CHAUDHURI* and SAHID HUSSAIN \\ Department of Chemistry, Indian Institute of Technology Guwahati, Guwahati 781039 \\ e-mail: mkc@iitg.ernet.in
}

MS received 16 April 2005; revised 6 August 2005

\begin{abstract}
An efficient synthesis of substituted quinolines has been achieved in a one-pot reaction from $o$-nitrobenzaldehyde and enolizable ketones using $\mathrm{SnCl}_{2} \cdot 2 \mathrm{H}_{2} \mathrm{O}$ as the reductant under microwave irradiation without any solvent or catalyst.
\end{abstract}

Keywords. Quinolines; o-nitrobenzaldehyde; enolizable ketone; $\mathrm{SnCl}_{2} .2 \mathrm{H}_{2} \mathrm{O}$; microwave; solvent-free synthesis.

\section{Introduction}

Quinoline derivatives have been well known not only in medicinal chemistry, because of their wide occurrence in natural products ${ }^{1}$ and drugs, ${ }^{2}$ but also in polymer chemistry, electronics and optoelectronics for their excellent mechanical properties. ${ }^{3}$ Diblock and triblock copolymers incorporating polyquinoline blocks have been found to undergo hierarchical selfassembly into a variety of nano- and meso-structures with interesting electronic and photonic functions. ${ }^{4}$ The Friedlaender synthesis of quinolines is a classic method, ${ }^{5}$ that involves two steps, wherein reduction of $o$-nitro aryl aldehyde is first achieved followed by the condensation of enolizable carbonyl compound in presence of a Bronsted or Lewis acid catalyst. The relative instability of the intermediate (o-amino aldehyde), with its strong tendency to undergo selfcondensation made such reactions rather complicated. Accordingly, there have been continuous efforts to develop clean and rapid newer protocols ${ }^{6}$ for the construction of quinoline-based structures. This has resulted in a few improved procedures for the synthesis of quinolines. As a part of our programme on the development of newer processes for organic transformations, ${ }^{7}$ our attention was drawn to two protocols, ${ }^{6 b, d}$ in one of which the $o$-aminobenzaldehyde was generated in situ and reacted immediately with an enolizable ketone to produce a quinoline ${ }^{6 b}$. This reaction was conducted in anhydrous ethanol under

\footnotetext{
*For correspondence
}

an atmosphere of nitrogen using $\mathrm{SnCl}_{2}$ as the reductant (e.g. $-\mathrm{NO}_{2}$ to $\mathrm{NH}_{2}$ ) and $\mathrm{ZnCl}_{2}$ as the facilitator of enolate formation from the enolizable ketones leading to the concomitant coupling condensation with the amine affording quinolines in rather low yields. The yields of products were remarkably increased by the addition of a significant amount of $4 \AA$ molecular sieves to the reaction solution. Evidently, the success of this methodology appears to depend on the avoidance of both water and air as well as the use of $\mathrm{ZnCl}_{2}$ as a Lewis acid catalyst. The other protocol ${ }^{6 \mathrm{~d}}$ was based on microwave-assisted coupling condensation reactions between acetophenones and 2-amino-acetophenones or benzophenones in the presence of diphenylphosphate (DPP) as the acid catalyst, which was essential to enhance cyclization, without the use of any solvent. In addition, there is a very recent report by Perumal et $a l^{8}$ on the synthesis of polysubstituted quinolines under solvent-free conditions having some advantages over many other protocols. However, here again the authors have used $o$-aminoarenes, rather than the corresponding $o$-nitroarenes, thereby entailing similar problems as emphasized above. Thus, it is quite imperative that quinolines synthesis requires further attention to obviate the need to maintain stringent experimental conditions, use of expensive catalysts, and prepare and isolate the $o$-amino cabonyls as synthetic precursors.

This paper reports an efficient solvent-free one-pot syntheses of quinolines achieved from $o$-nitrobenzaldehyde and enolizable ketones using $\mathrm{SnCl}_{2} \cdot 2 \mathrm{H}_{2} \mathrm{O}$ and subjecting them to microwaves. 
Table 1. Microwave-assisted synthesis of quinolines under solvent-free conditions.

Eryl aldehyde

*Isolated yield

\section{Experimental}

\subsection{General}

All procedures were carried out on the bench top. Reagent-grade chemicals were used without further purification. The substrates and solvents were used as received. The products were characterized by comparing their spectral data recorded on a Nicolet Impact-410 Fourier Transform Infrared Spectrophotometer, Varian-400 FT NMR, Perkin-Elmer 2400 autometic CHNS analyzer and Perkin-Elmer Precisely Clarus 500 Mass Spectrometer. TLC and column chromatography were performed on silica gel $\mathrm{G}_{254}$ and 60-120 mesh respectively.

\subsection{Synthesis of quinolines. A general procedure}

Typically, 2-nitro aryl aldehyde $(2 \mathrm{mmol})$ and an enolizable ketone $(2 \mathrm{mmol})$ were uniformly mixed with $\mathrm{SnCl}_{2} \cdot 2 \mathrm{H}_{2} \mathrm{O}(6 \mathrm{mmol})$. The resulting mixture 
was then irradiated with microwaves in a microwave oven (Samsung model\# CE118KF) at 1050W (70\% of total power) for 5 minutes $(3+2$ with an intermission of 5 minutes). The reaction mixture was cooled at room temperature and rendered basic $(\mathrm{pH}$ 8 ) with $10 \% \mathrm{NaHCO}_{3}$, and then extracted with ethyl acetate. The organic layer was washed with brine, dried over $\mathrm{Na}_{2} \mathrm{SO}_{4}$, and evaporated to leave behind the crude product, which was further purified by column chromatography over silica gel (hexane: ethyl acetate $:: 4: 1$ ). Details of the substrates used, products obtained and yields are all set out in table 1 .

\section{Results and discussion}

In view of the problems encountered in quinoline synthesis, a relatively more versatile yet simplified procedure was perceived, based on the reasoning that the substrates like $o$-nitrobenzaldehyde and enolizable ketones could be made to interact in the presence of $\mathrm{SnCl}_{2}$ under microwave irradiation without using any solvent. Microwave synthesis has received attention as a new strategy for organic synthesis due to the fact that many reactions seem to proceed with much alacrity under such conditions as opposed to the corresponding thermal-assisted reactions. ${ }^{9}$ Our arguments have been that under microwave irradiation, the reduction of $o$-nitrobenzaldehyde by $\mathrm{SnCl}_{2}$ to the corresponding amino derivatives, in situ enolization of the chosen ketones, and enhanced dipoledipole interactions between the activated reaction intermediates would lead to an instantaneous condensation to afford quinolines without the use of any solvent or catalyst. The strategy worked well affording the desired products in respectable yields (scheme 1). Notably, the present reactions have been relatively faster, as anticipated, compared to those of Perumal et $a l .{ }^{8}$ It is necessary to mention that in all cases the conversion was less than $100 \%$. Small amounts of starting materials were recovered after each reaction. Temperature of the reaction mixture recorded immediately after microwave irradiation for the given period of time was found to be c.a. $105^{\circ} \mathrm{C}$. To ensure the contribution of microwave effects, the re-

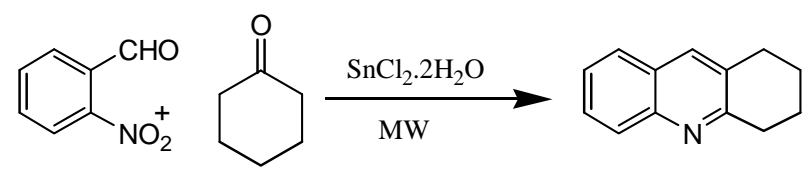

Scheme 1. actions in entries 1 and 7 were examined by simply heating in a preheated oil-bath being maintained at $105^{\circ} \mathrm{C}$ for the same duration as mentioned in the typical procedure with microwave irradiation. A very small amount (1-3\%) of quinoline derivative was isolated in each case leading us to state that, under the given experimental conditions, microwave irradiation is responsible for bringing about the reaction. A wide range of enolizable ketones (cycloalkyl, $n$-alkyl, alkyl aryl) were screened in order to ascertain the scope of the present reaction protocol and the results are summarized in table 1. It is evident from the results that alkyl and cycloalkyl enolizable ketones readily cyclized with the in situ generated $o$ amino benzaldehyde to afford the corresponding quinolines ${ }^{10}$ in good to very good yields. However, lower yields were observed with alkyl aryl ketones (entries 7 and 8) and no quinoline formation was observed with a hydroxy-substituted aromatic ring of an alkyl aryl ketone (entry 9).

\section{Conclusion}

We have developed a solvent-free, microwave-assisted, very facile protocol for the synthesis of quinolines without the intervention of any acid catalyst and molecular sieves. Another important advantage is the redundancy of extra preparation and isolation of $o$-amino benzaldehyde. This protocol offers scope for further work involving a variety of substrates with varied substituents. The microwave-facilitated version of quinoline synthesis is expected to be a viable alternative to the classic Friedlaender synthesis, owing to several advantages summarized herein.

\section{Acknowledgement}

SH thanks the Council of Scientific and Industrial Research, New Delhi for a fellowship.

\section{References}

1. Morimoto Y, Matusuda F and Shirahama H 1991 Synlett 202; (b) Michael J P 1997 Natl. Prod. Rep. 14 605

2. Markees D G, Dewey V C and Kidder G W $1970 \mathrm{~J}$. Med. Chem. 13 324; (b) Campbell S F, Hardstone J D and Palmer M J 1998 J. Med. Chem. 311031

3. (a) Jenekhe S A, Lu L and Alam M M 2001 Macromolecules 34 7315; (b) Agrawal A K and Jenekhe S A 1993 Chem. Mater. 5 633; (c) Jegou G and Jenekhe S A 2001 Macromolecules 347926 
4. (a) Jenekhe S A and Chen X L 1998 Science 279 1903; (b) Jenekhe S A and Chen X L 1999 Science 283372

5. Cheng C-C and Yan S-J 1982 Org. React. 2837

6. (a) Cho C S, Kim B T, Kim T-J and Shim S C 2001 Chem. Commun. 2576; (b) McNaughton B R and Miller B L 2003 Org. Lett. 54257 (c) Ranu B C, Hajra A, Dey S S and Jana U 2003 Tetrahedron 59 813; (d) Song S J, Cho S J, Park D K, Kwon T W and Jenekhe S A 2003 Tetrahedron Lett. 44 255; (e) Cho C S, Kim B T, Choi H-J, Kim T-J and Shim S C 2003 Tetrahedron 59 7997; (f) Motokura K, Mizugaki T, Ebitaniu K and Kaneda K 2004 Tetrahedron Lett. 45 6029

7. (a) Kantam M L, Kavita B, Neeraja V, Haritha Y, Chaudhuri M K and Dehury S K 2003 Tetrahedron Lett. 44 9029; (b) Kantam M L, Kavita B, Neeraja V, Haritha Y, Chaudhuri M K and Dehury S K 2005 Adv. Synth. Catal. 347 641; (c) Kantam M L, Neeraja V, Kavita B, Neelima B, Chaudhuri M K and Hussain S 2005 Adv. Synth. Catal. 347763

8. Arumugam P, Karthikeyan G, Atchudan R, Murlidharan D and Perumal P T 2005 Chem. Lett. 34314

9. Perreux L and Loupy A 2001 Tetrahedron 57 9225; (b) Varma R S 1999 Green Chem. 43; (c) Elander N, Jones J R, Lu S-Y and Stone-Elander S 2000 Chem. Soc. Rev. 29 239; (d) Loupy A, Perreux L, Liagre M, Burle K and Moneuse M 2001 Pure Appl. Chem. 73161

10. Selected spectral data for products: Run 1. 2,3 Dimethyl-quinoline. ${ }^{1} \mathrm{H} \quad \mathrm{NMR} \quad\left(400 \mathrm{MHz}, \mathrm{CDCl}_{3}\right)$ : $\delta=2.42(s, 3 \mathrm{H}), 2.67(s, 3 \mathrm{H}), 7.43(t, J=7.6 \mathrm{~Hz}, 1 \mathrm{H})$, $7.60(t, J=8.4 \mathrm{~Hz}, 1 \mathrm{H}), 7.68(d, J=8.0 \mathrm{~Hz}, 1 \mathrm{H}), 7.80$ $(s, 1 \mathrm{H}), 7.98(d, J=8.4 \mathrm{~Hz}, 1 \mathrm{H}) ;{ }^{13} \mathrm{C}$ NMR $(100 \mathrm{MHz}$, $\left.\mathrm{CDCl}_{3}\right): 19 \cdot 7,23 \cdot 6,125 \cdot 5,126 \cdot 5,127 \cdot 1,128 \cdot 0,128 \cdot 20$, 129.6, 135.0, 146.3, 159.7; anal. calcd. for $\mathrm{C}_{11} \mathrm{H}_{11} \mathrm{~N}$ : C $84.04, \mathrm{H} 7 \cdot 05, \mathrm{~N} 8.91 \%$; found: C $83.99, \mathrm{H} 7 \cdot 11, \mathrm{~N}$ $8.90 \% ; \mathrm{MS}(\mathrm{m} / \mathrm{z}): 157\left(\mathrm{M}^{+}\right)$

2. 2-Ethyl-3-methyl-quinoline. ${ }^{1} \mathrm{H}$ NMR $(400 \mathrm{MHz}$, $\left.\mathrm{CDCl}_{3}\right): \delta=1.28(s, 3 \mathrm{H}), 2.40(s, 3 \mathrm{H}), 2.77(q, J=$ $7.4 \mathrm{~Hz}, 2 \mathrm{H}), 7.42(t, J=7.6 \mathrm{~Hz}, 1 \mathrm{H}), 7.57(t, J=$ $8.4 \mathrm{~Hz}, 1 \mathrm{H}), 7.68(d, J=8.0 \mathrm{~Hz}, 1 \mathrm{H}), 7.82(s, 1 \mathrm{H}), 7.96$ $(d, J=8.4 \mathrm{~Hz}, 1 \mathrm{H}) .{ }^{13} \mathrm{C}$ NMR $\left(100 \mathrm{MHz}, \mathrm{CDCl}_{3}\right)$ : $\delta=19 \cdot 6,22 \cdot 5,25 \cdot 2,125 \cdot 5,126 \cdot 5,127 \cdot 0,128 \cdot 0,128 \cdot 1$,
$129 \cdot 6,135 \cdot 0,146 \cdot 5,159 \cdot 2$; anal. calcd. for $\mathrm{C}_{12} \mathrm{H}_{13} \mathrm{~N}$ : C 84.17 H 7.65, N 8.18\%; found: C 84.09 H 7.70, N $8 \cdot 21 \%$; MS $(\mathrm{m} / \mathrm{z}): 171\left(\mathrm{M}^{+}\right)$.

4. 1,2,3,4-Tetrahydro-acridine. ${ }^{1} \mathrm{H}$ NMR $(400 \mathrm{MHz}$, $\left.\mathrm{CDCl}_{3}\right): \delta=1.86-1.91(m, 2 \mathrm{H}), 1.96-2.00(m, 2 \mathrm{H})$, $2.96(t, J=6.4 \mathrm{~Hz}, 2 \mathrm{H}), 3 \cdot 12(t, J=6.8 \mathrm{~Hz}, 2 \mathrm{H}), 7 \cdot 42$ $(t, J=7.4 \mathrm{~Hz}, 1 \mathrm{H}), 7.59(t, J=9.6 \mathrm{~Hz}, 1 \mathrm{H}), 7.68(d d$, $J=1.2 \mathrm{~Hz}, J=8.0 \mathrm{~Hz}, 1 \mathrm{H}), 7.78(s, 1 \mathrm{H}), 7.97(d, J=$ $8.4 \mathrm{~Hz}, 1 \mathrm{H}) ;{ }^{13} \mathrm{C}$ NMR $\left(100 \mathrm{MHz}, \mathrm{CDCl}_{3}\right): \delta=23 \cdot 0$, $23 \cdot 3,29 \cdot 3,33 \cdot 6,125 \cdot 4,126 \cdot 7,127 \cdot 0,128 \cdot 0,128 \cdot 3$, 130.8, 134.8, 146.4, 159.0; anal. calcd. for $\mathrm{C}_{13} \mathrm{H}_{13} \mathrm{~N}$ : C $85.21 \mathrm{H} \mathrm{7.15}, \mathrm{N} 7.64 \%$; found: C $85.18 \mathrm{H} 7 \cdot 19$, N 7.63\%; MS ( $\mathrm{m} / \mathrm{z}): 183\left(\mathrm{M}^{+}\right)$

5. 6,7,8,9,10,11-Hexahydro-cycloocta[b] quinoline. ${ }^{1} \mathrm{H}$ NMR $\left(400 \mathrm{MHz}, \mathrm{CDCl}_{3}\right): \delta=1.37-1.91(m, 8 \mathrm{H})$, $2.94(t, J=6.4 \mathrm{~Hz}, 2 \mathrm{H}), 3.21(t, J=6.0 \mathrm{~Hz}, 2 \mathrm{H}), 7.45$ $(t, J=8.0 \mathrm{~Hz}, 1 \mathrm{H}), 7.61(t, J=8.8 \mathrm{~Hz}, 1 \mathrm{H}), 7.70(d$, $J=8.0 \mathrm{~Hz}, 1 \mathrm{H}), 7.80(s, 1 \mathrm{H}), 7.99(d, J=8.4 \mathrm{~Hz}, 1 \mathrm{H})$ ${ }^{13} \mathrm{C}$ NMR $\left(100 \mathrm{MHz}, \mathrm{CDCl}_{3}\right): \delta=27 \cdot 1,28 \cdot 9,29 \cdot 8$, $32 \cdot 3,35 \cdot 5,40 \cdot 1,125 \cdot 6,126 \cdot 6,127 \cdot 2,128 \cdot 2(2 \mathrm{C}), 134 \cdot 3$ (2C), 146.0, 164.4; anal. calcd. for $\mathrm{C}_{15} \mathrm{H}_{17} \mathrm{~N}: \mathrm{C} 85 \cdot 26 \mathrm{H}$ 8.11, N 6.63\%; found: C 85.18 H 8.22, N 6.60\%; MS $(\mathrm{m} / \mathrm{z}): 211\left(M^{+}\right)$

6. 6,7,8,9,10,11,12,13,14,15-Decahydro-5-aza-cyclododeca [b]naphthalene. ${ }^{1} \mathrm{H} \mathrm{NMR}\left(400 \mathrm{MHz}, \mathrm{CDCl}_{3}\right)$ : $\delta=1.42-1.56(m, 12 \mathrm{H}), 1.78-1.82(m, 2 \mathrm{H}), 1.94-1.98$ $(m, 2 \mathrm{H}), 2.83(t, J=8.0 \mathrm{~Hz}, 2 \mathrm{H}), 3.03(t, J=8.0 \mathrm{~Hz}$, $2 \mathrm{H}), 7.42(t, J=6.4 \mathrm{~Hz}, 1 \mathrm{H}), 7.60(t, J=6.8 \mathrm{~Hz}, 1 \mathrm{H})$, $7.70(d d, J=1.2 \mathrm{~Hz}, J=8.4 \mathrm{~Hz}, 1 \mathrm{H}), 7.89(s, 1 \mathrm{H}), 7.99$ $(d, J=8.4 \mathrm{~Hz}, 1 \mathrm{H}),{ }^{13} \mathrm{C}$ NMR $\left(100 \mathrm{MHz}, \mathrm{CDCl}_{3}\right)$ : $\delta=23 \cdot 1,23 \cdot 2,25 \cdot 6,26 \cdot 1,26 \cdot 6,26 \cdot 8,28 \cdot 5,29 \cdot 7,29 \cdot 8$, $32 \cdot 8,125 \cdot 4,126 \cdot 6,127 \cdot 0,128 \cdot 1,128 \cdot 2,134 \cdot 7,135 \cdot 6$, 146.3, 162.4; anal. calcd. for $\mathrm{C}_{19} \mathrm{H}_{25} \mathrm{~N}$ : C 85.34 H 9.42, N 5.24\%; found: C 85.28 H 9.52, N 5.20\%; MS (m/z): $267\left(M^{+}\right)$

8. 3-Methoxy-5,6-dihydro-benzo[c] acridine. ${ }^{1} \mathrm{H}$ NMR (400 MHz, $\left.\mathrm{CDCl}_{3}\right): \delta=2.97(t, J=6.4 \mathrm{~Hz}, 2 \mathrm{H})$, $3.10(t, J=7.6 \mathrm{~Hz}, 2 \mathrm{H}), 3.87(s, 3 \mathrm{H}), 7.45(t, J=$ $7.2 \mathrm{~Hz}, 1 \mathrm{H}), 7.62(t, J=6.8 \mathrm{~Hz}, 1 \mathrm{H}), 7.71(d, J=$ $8.0 \mathrm{~Hz}, 1 \mathrm{H}), 7.87(s, 1 \mathrm{H}), 8.09(d, J=8.4 \mathrm{~Hz}, 1 \mathrm{H}), 8.50$ $(d, J=8.8 \mathrm{~Hz}, 1 \mathrm{H})$; anal. calcd. for $\mathrm{C}_{18} \mathrm{H}_{15} \mathrm{NO}: \mathrm{C} 82.73$ H 5.79, N 5.36\%; found: C 82.66 H 5.88, N 5.41\%; MS $(\mathrm{m} / \mathrm{z}): 261\left(M^{+}\right)$ 